\title{
UAS BASED RAPID MAPPING AND ASSESSMENT OF SAND DUNES ALONG THE BULGARIAN BLACK SEA COST: THE CASE OF "CORAL" BEACH, BULGARIA
}

DOI: http://dx.doi.org/10.18509/GBP.2019.67

UDC: 528.94:551.435.3(262.5)(497.2)

\author{
Stelian Dimitrov ${ }^{1}$ \\ Vesela Savova ${ }^{2}$ \\ ${ }^{1}$ Sofia University “St. Kliment Ohridski”, Bulgaria \\ ${ }^{2}$ Ministry of Environment and water, Bulgaria
}

\begin{abstract}
This article aims to present the approach, the methods and the results in the application of a UAS based rapid mapping and assessment of the state of sand dunes along the Bulgarian Black Sea coast. Even though these typical and unique natural phenomena are priority habitats and protected sites, they are under constant investment pressure during the last 20 years, causing the decrease of their coverage. Regarding these problems, there is an urgent need for developing and using new, more efficient approaches and methods for rapid mapping, assessment and monitoring, especially in the most problematic and conflict areas, exposed to human impact. The UAS based rapid mapping and assessment has the capabilities for providing the necessary high-quality geospatial data, which can scientifically improve the decision-making processes, regarding the management and protection of the sand dunes in Bulgaria.
\end{abstract}

Keywords: Unmanned Aerial Systems (UAS), rapid mapping, geospatial data and information, sand dunes

\section{INTRODUCTION}

In recent years the use of Unmanned Aerial Systems (UAS) for operational collection of geographic data is growing continuously" [1]. Compared to traditional remote sensing approaches, UAS provide flexible, effective and easy to use platform at reasonable price for capturing high-resolution geospatial data. For this reason, they are a highly effective tool for mapping, assessment and monitoring of small scale, dynamically developing geosystems, which makes environmental monitoring one of the key pillars of UAS-based research [2]. The integrated application of UAS based remote sensing with in-situ field observations, has huge research potential, providing valuable information in very effective way [3-7].

The presented approach, and all methods and research techniques associated with it, are particularly appropriate for mapping and inventory of small-sized, but complex as a structure, as well as sensitive natural habitats and ecosystems, such as, the sand dunes along the sea coasts. The object of research of the current paper are the sand dunes along the Bulgarian Black Sea coast. Such structures are very typical feature of the Bulgarian Black Sea coast, but in the recent years they have been exposed to a significant anthropogenic pressure resulting from the continuously growing urbanization in the coastal areas. Dunes are specific and sensitive geosystems and their recovery is either very slow or impossible [8]. Despite the recent efforts to protect them, their area is 
constantly shrinking, and currently they are occupying less than $10 \%$ of the Bulgarian Black Sea coast [9].

Apart from being exposed to a continuous anthropogenic pressure, the dunes and dune systems have comparatively limited spatial extent, and at the same time - complex structure. For this reason, their mapping, inventory and regular monitoring requires the use of highly precise, but inexpensive and flexible geospatial tools, requiring less time for operation and application.

In this regard, the present research aims to demonstrate the approach, the methods used and the results obtained in the application of a UAS based rapid mapping and assessment of the current state of sand dunes along the Bulgarian Black Sea coast. In order to explore and evaluate the potential of the applied approach and methodology, a specific case study was selected - this is the beach "Koral", in Municipality of Tsarevo, Burgas district, Bulgaria.

\section{MATERIALS AND METHODS}

Study area: the Coral beach is located on South-Bulgarian Black Sea cost, next to the village of Losnets, which is situated about $60 \mathrm{~km}$ south of the Bourgas city. This beach is one of the most problematic areas in the recent years, there is an ongoing conflict between the intensity of tourism development and the efforts for preservation of the natural heritage in the country.

Approach and methodology:The rapid mapping procedure of the target territory includes three main stages: (a) Planning and implementing an automated flight mission combined with an in-situ verification; (b) photogrammetric processing of collected geospatial data / images in camera conditions and generation of derived products (orthophoto map and digital models of surface and terrain); c) spatial analysis and mapping of dunes and dunes systems in GIS environment, and spatial benchmarking with data from previous mappings carried out by other projects and methods applied.

The aerial shooting of Coral Beach was performed using a professional UAS, type "Flying Wing "- Ebee, equipped with a photogrammetric camera with a RGB resolution of 5,472 x 3,648 px (3: 2), supporting RTK / PPK geotagging (fig 1).
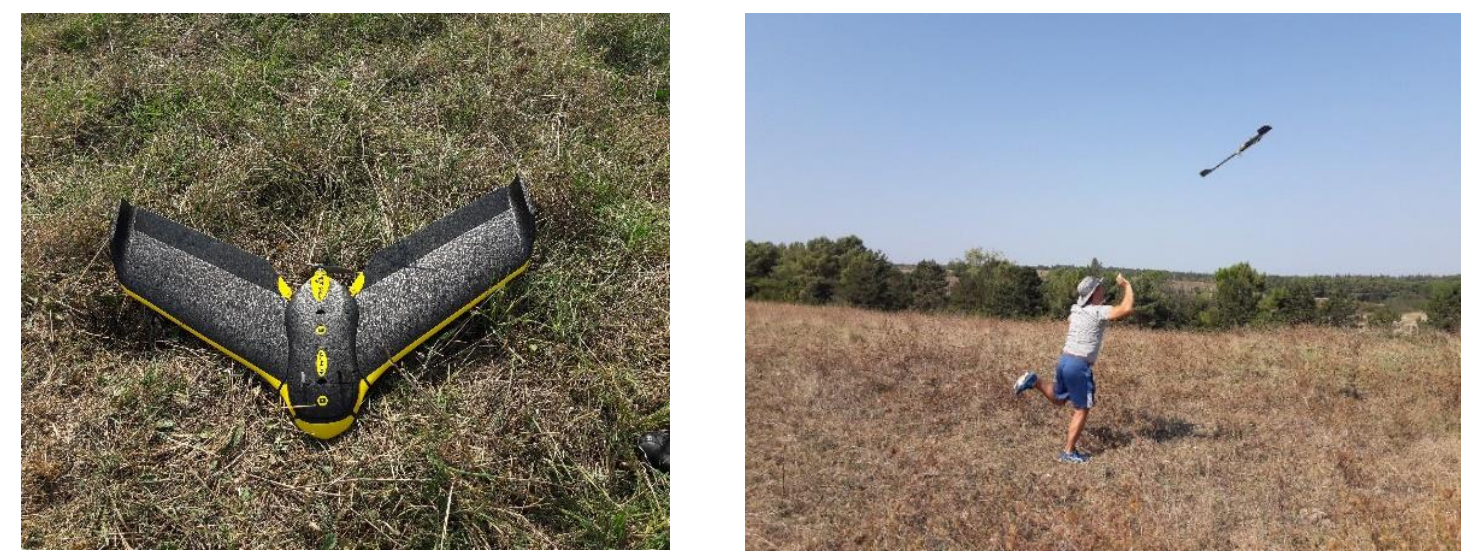

Figure 1. Professional UAS, type "Flying Wing “- Ebee

The chosen period for shooting and mapping the targeted site was during the peak of the tourist season (end of August 2018), not only because of the stable weather conditions for flying missions with UAS and the appropriate vegetation stages of the typical habitats of 
plant species at the dunes, but also because this is the period when the concentrated anthropogenic impact is present.

The scope of the site is carefully considered in the preparatory phase, which is done through a preliminary analysis of the available data on the distribution of the sand dunes in the area of Coral beach. On this basis is a polygon is defined - about $800 \mathrm{~m}$ long (NWSE direction) and about $600 \mathrm{~m}$ wide. (SW-NE direction), which is assigned in a specialized platform for the planning of flight missions - E-motion (Fig. 2).

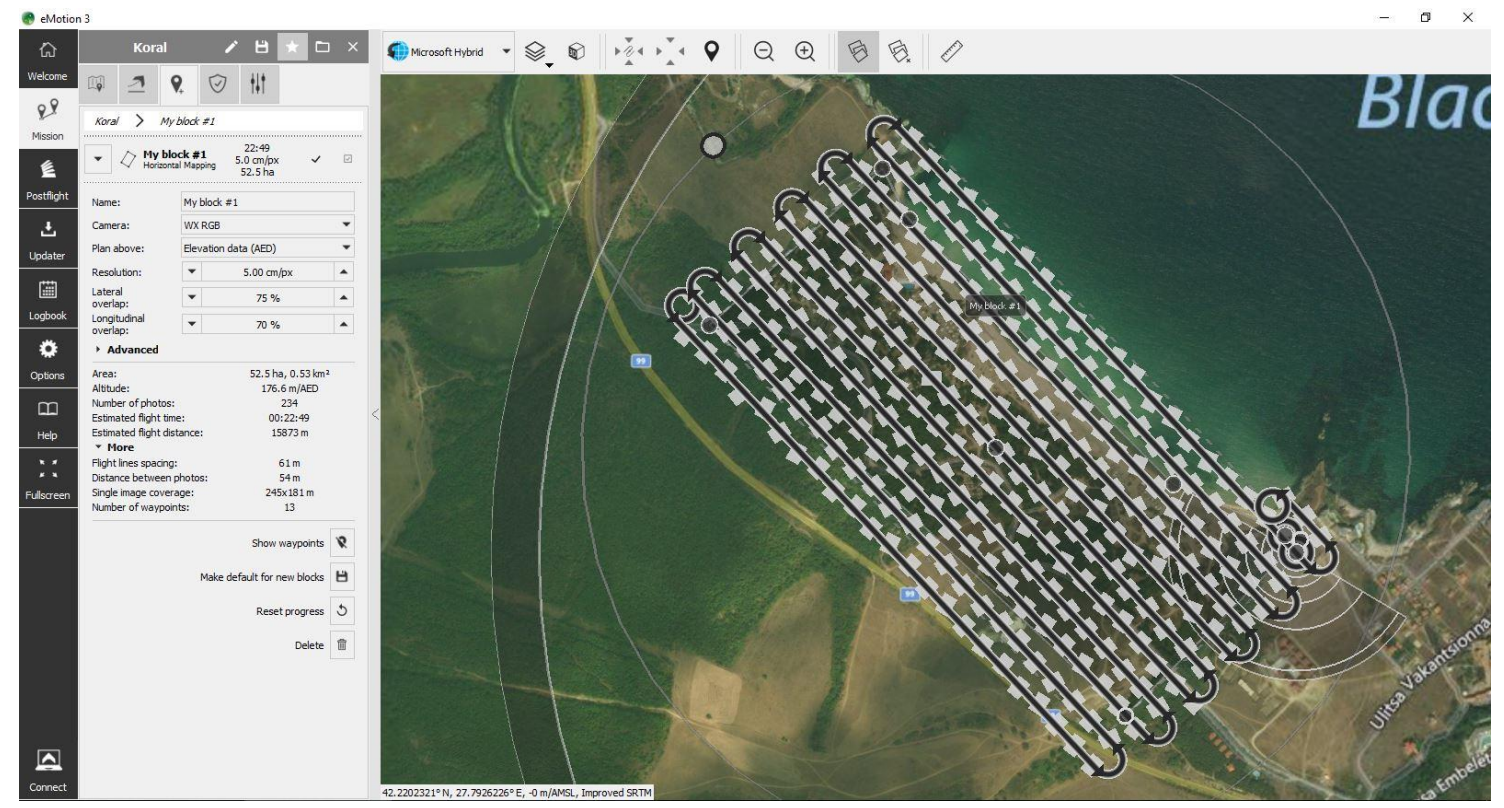

Figure 2. ,eMotion 3“ platform with the parameters of the flight

Once set as parameters, the mission can be carried out unlimited number of times in an identical way, which in turn allows the provision of monitoring data with an extremely high degree of comparability of the individual parameters being monitored.

As a result of the mission, 260 individual geotagged images were captured, overlapping to a $70 \%$ in order to provide a more precise digital surface model. In addition, 12 control points captured with the RTK-GNSS receiver were used to increase the vertical and horizontal accuracy of the model.

The photogrammetric processing was performed using the Pix4Dmapper software platform, where an orthophoto plan, a digital surface model and a digital terrain model were generated, which were subsequently analyzed in a GIS environment (ArcGIS platform was used).

Along with the implementation of the flight mission and the capture of the control points, a field work was carried out on the territory, and additional photo material was collected for the status of the sand dunes. The total duration of the field stage (including the conduct of the mission) amounted to 1 hour and 45 minutes, which illustrates the high degree of time efficiency of the system used.

\section{RESULTS}

As a result of the photogrammetric processing of the captured images, an orthophoto map and a digital model of the surface with a resolution of $5.4 \mathrm{~cm} / \mathrm{px}$ were generated, which in turn allow for a clear classification of the landforms and the surface cover in the studied area, including the formed dunes and dune systems (Fig. 3) 

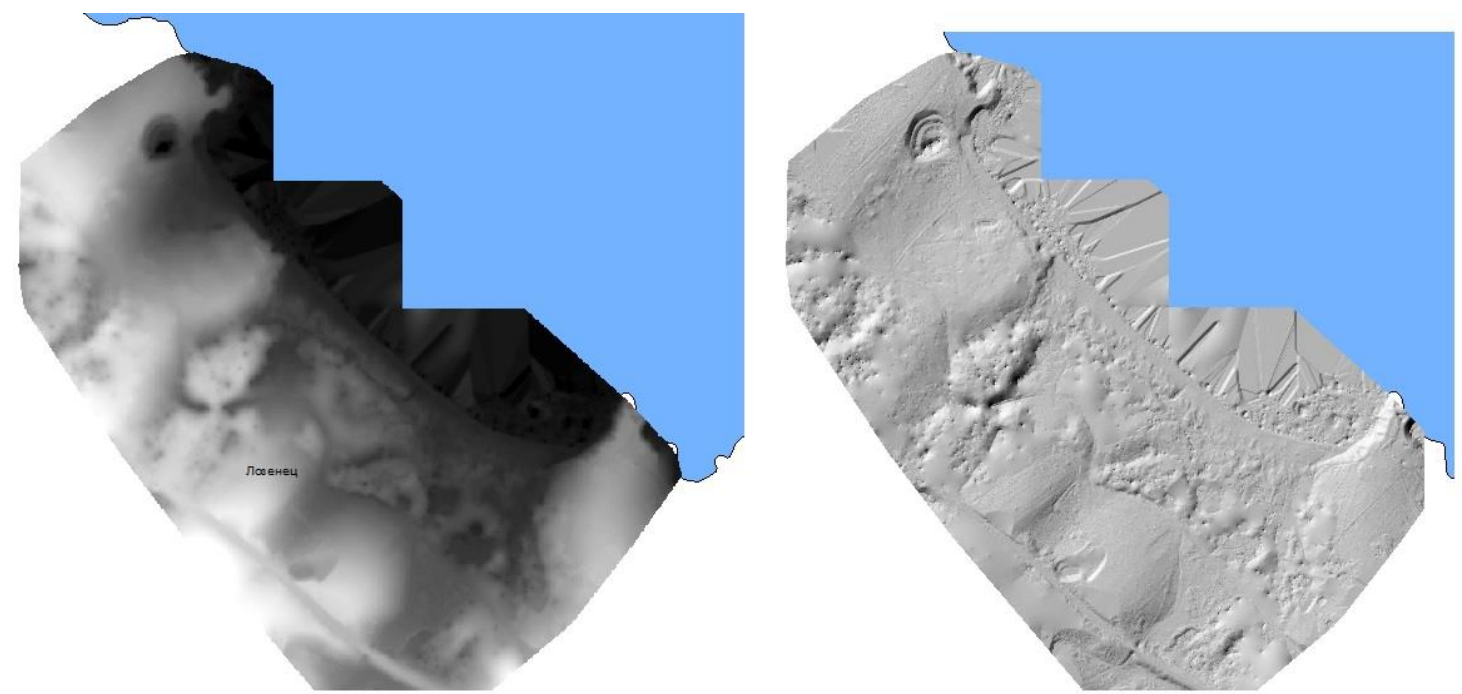

Figure 3. Generated DSM and hilshade model of the study area

On this basis, along with additional in-situ verification information, the boundaries of the sand dunes are mapped by using combination of UAS based mapping (fi.4)

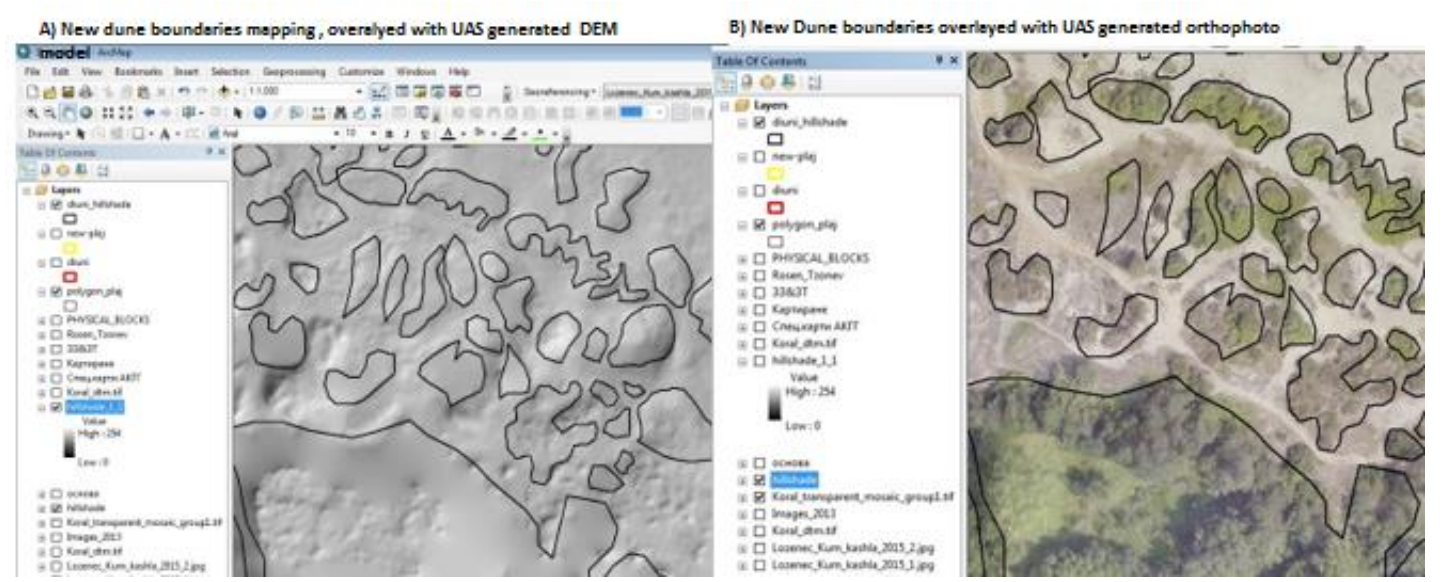

Figure 4. Overlay of the dunes boundaries and the products, generated from the UAS missions- $\operatorname{DEM}(\mathrm{A})$ and orthophoto image(B)

By collecting additional terrain information (including geotagged photo material), individual dunes are identified as natural habitats. This information, along with the geotagged images, is integrated into the attribute component of the geobase data created for the study (fig.5).

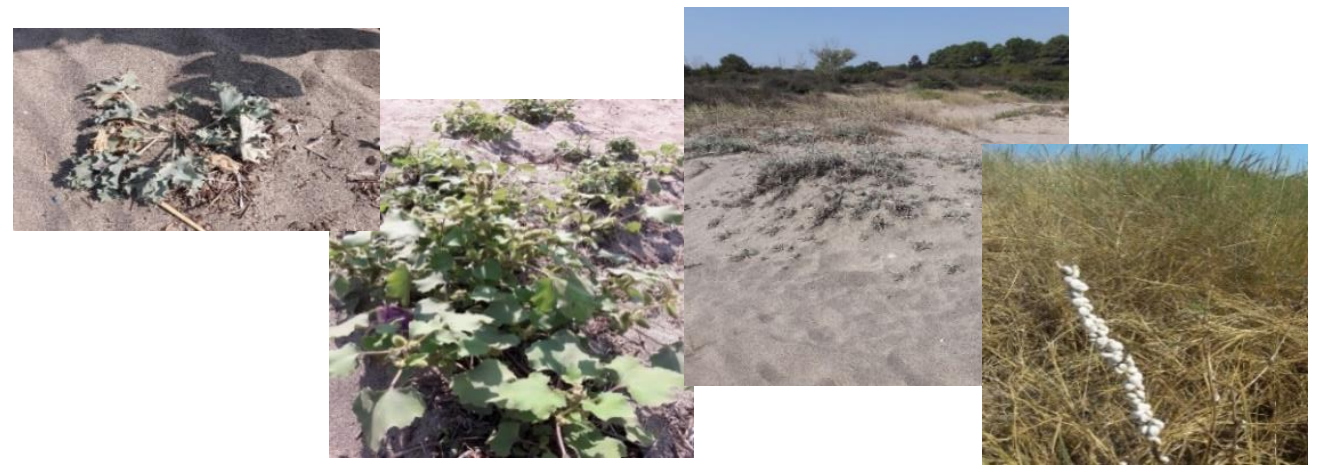

Figure 5. Images of: Eryngium maritimum, Elymion gigantea, Ammophila arenaria и Crambe maritima 
The figure below clearly shows the high level of detail of the generated geographic information on the distribution of sand dunes and dune systems in the studied area compared to the data currently used for the distribution of dunes as natural habitats by the Ministry of Environment and Waters in Bulgaria. The data is collected and processed within the framework of the project "Mapping and Determination of the Conservation Status of Natural Habitats and Species - Phase I"[10], implemented through financing under OP "Environment" 2007-2013.

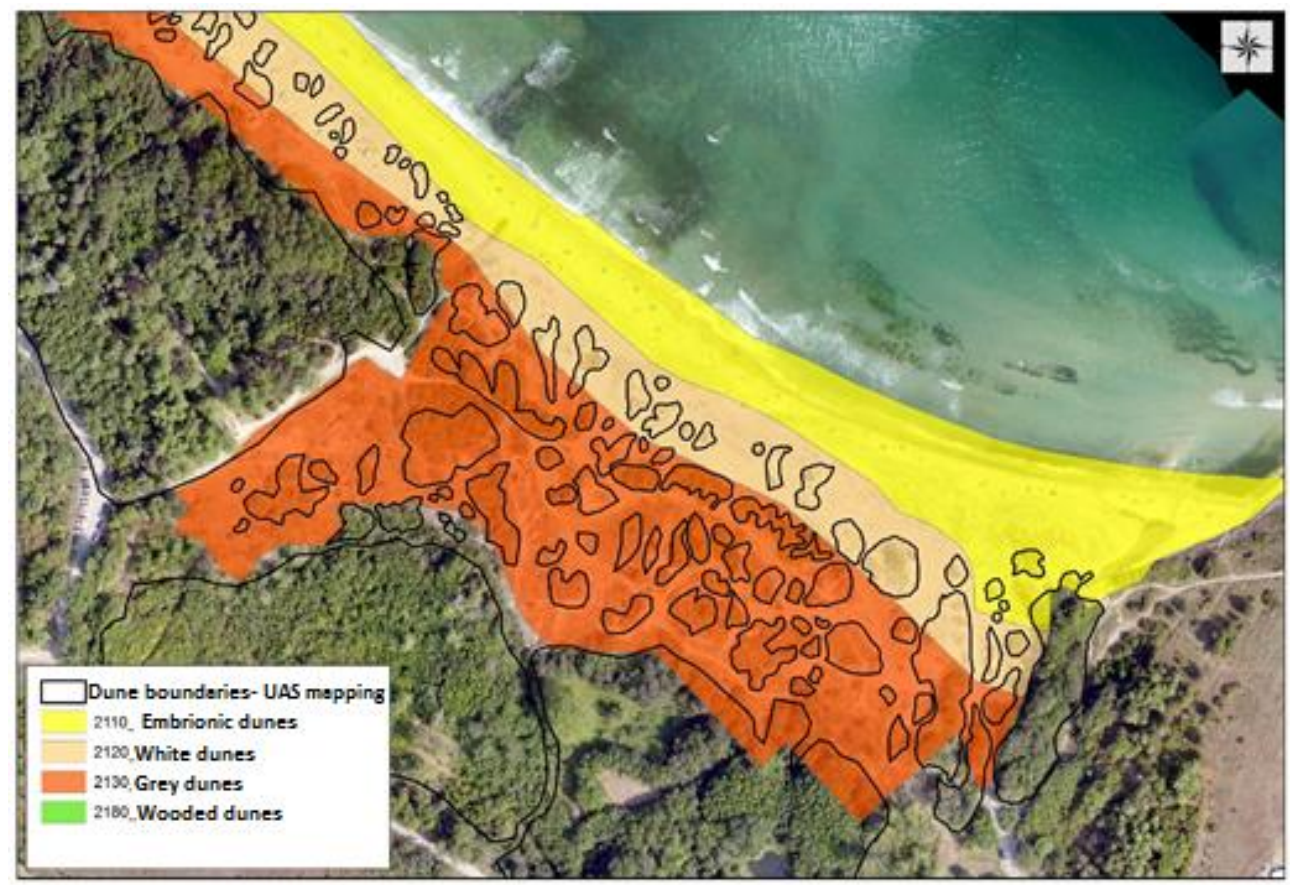

Figure 6. Spatial configuration and distribution of dunes and dunes systems, resulted from UAS based mapping compared with information from project

"Mapping and Determination of the Conservation Status of Natural Habitats and Species - Phase I"

\section{DISCUSION}

In the present study, a rapid mapping and classification approach of the sand dunes and dune systems as natural habitats within the Coral beach, located in the southern part of the Bulgarian Black Sea coast, was applied. By using remote-sensing techniques, based on the use of UAS platform, very detailed and precise information has been gathered, not only for the distribution and spatial configuration of these specific micro-ecosystems, but also for the characteristics that determine their classification and typology as natural habitats.

The achieved high degree of spatial resolution combined with the low cost and flexibility of the applied approach as well as the relatively short time spent on the field work, show the significant potential of using the applied integration of UAS based remote sensing with traditional field research and other geospatial technologies for monitoring purposes. 


\section{REFERENCES}

[1] Pajares, G. Overview and Current Status of Remote Sensing Applications Based on Unmanned Aerial Vehicles (UAVs), Photogrammetric Engineering \& Remote Sensing, Volume 81, Number 4, April 2015, pp. 281-330(50);

[2] Hardin, P.J., and T.J. Hardin, 2010. Small-scale remotely piloted vehicles in environmental research, Geography Compass, 4(9):1297-1311.

[3] Dimitrov, S., Georgiev G., Georgieva M., Gluschkova M., Chepisheva V., Mirchev P. and Zhiyanski M. "Integrated assessment of urban green infrastructure condition in Karlovo urban area by in-situ observations and remote sensing", One Ecosystem, 3, e21610. https://doi.org/10.3897/oneeco.3.e21610 (2018).

[4] Colomina, I., Blázquez M., Molina P., Parés M. and Wis M. "Towards a new paradigm for high-resolution low-cost photogrammetry and remote sensing, ISPRS", Int. Arch. Photogramm. Remote Sens. Spatial Inform., Sci., XXXVII-B1, 1201-1206 (2008).

[5] Cho, G., Hildebrand A., Claussen J., Cosyn P. and Morris S. "Pilotless aerial vehicle systems: size, scale and functions", Coordinates, 9, 8-16 (2013).

[6] Mayr, W. "Unmanned aerial systems - for the rest of us", 54th Photogrammetric Week, Institut für Photogrammetrie, Universität Stuttgart, 151-163 (2013).

[7] Petrie, G. "Commercial operation of lightweight UAVs for aerial imaging and mapping", GEOInformatics, 16, 28-39 (2013).

[8] Doody,J.P., 2004. Coastal habitats to get bigger and better? Proceedings of Littoral 2004 7th International Symposium:Delivering Sustainable Coasts: Connecting Science and Policy, (Aberdeen, Scotland), pp. 83-88

[9] Stancheva M, Ratas U, Orviku K, Palazov A, Rivis R, Kont A, PeychevV, Tõnisson H, Stanchev H (2011) Sand dune destruction due toincreased human impacts along the Bulgraian Black Sea andEstonian Baltic Sea coasts. J Coast Res 64:324-328.

[10] „Mapping and Determining the Nature Conservation Status of Natural Habitats and Species - Phase I",2013, https://www.moew.government.bg/bg/priroda/proekti/proekti-po-opos/ 